\title{
LUTA PELA TERRA E SOBERANIA ALIMENTAR: O CASO DO QUILOMBO CAMPO GRANDE, NO SUL DE MINAS GERAIS
}

José Roberto Salvaterra ${ }^{1}$

RESUMO: Após conquistarem mais de 9 mil assentamentos nas últimas quatro décadas e de construção contínua da luta pela terra através das ocupações, os movimentos socioterritoriais assumem, na atualidade, uma preocupação também com a orientação das questões alimentares, especialmente por meio do ideário de Soberania Alimentar, elencada pela Via Campesina. Como exemplo, consta o Movimento dos Trabalhadores Rurais Sem-Terra (MST) que tem sido um dos maiores expoentes da luta pela terra e por Soberania Alimentar, onde em Campo do Meio - MG, através do Quilombo Campo Grande, encontramos essas duas facetas de disputa territorial e de desenvolvimento. Juntamente com a perspectiva da indissociabilidade, o trabalho se desenvolveu como parte das ações de programas de extensão da UNIFAL-MG em acompanhamento a visitas de campo, comercialização e manifestações políticas. A principal contribuição que oferecemos com este trabalho é a discussão sobre como a luta pela terra e por Soberania Alimentar têm se constituído no Quilombo Campo Grande e como as duas se entrelaçam com objetivos comuns - de se contrapor ao modelo hegemônico e de alçar modelos justos e sustentáveis de desenvolvimento contrários ao estipulado pelo capitalismo.

PALAVRAS-CHAVE: Questão Agrária; Agroecologia; Campesinato; Soberania Alimentar; Desenvolvimento Territorial.

\section{STRUGGLE FOR LAND AND FOOD SOVEREIGNTY: THE CASE OF QUILOMBO CAMPO GRANDE IN THE SOUTH OF MINAS GERAIS}

\begin{abstract}
After conquering more than 9,000 rural settlements in the last four decades and the continuous construction of the struggle for land through occupations, the socioterritorial movements are currently also concerned with the orientation of food issues, especially through the ideas of Food Sovereignty proposed by Via Campesina. As an example, there is the Landless Worker's Movement (MST) which has been one of the greatest exponents of the struggle for land and for Food Sovereignty, where in Campo do Meio - MG, through Quilombo Campo Grande, we find these two facets of territorial dispute and development. Along with the perspective of inseparability, the work was developed as part of the actions of the extension programs of UNIFAL-MG in follow-up to
\end{abstract}

1 Bacharel em Geografia pela Universidade Federal de Alfenas (UNIFAL-MG). E-mail: jose.salvaterra@sou.unifal-mg.edu.br 
fieldworks, commercialization and political demonstrations. The main contribution we offer with this work is the discussion on how the struggle for land and for Food Sovereignty have been constituted in Quilombo Campo Grande and how the two intertwine with common goals - to oppose the hegemonic model and to raise fair and sustainable development contrary to what is stipulated by capitalism.

KEYWORDS: Agrarian Question; Agroecology; Peasantry; Food Sovereignty; Territorial Development.

\section{LUCHA POR LA TIERRA Y LA SOBERANÍA ALIMENTARIA: EL CASO DE QUILOMBO CAMPO GRANDE EN EL SUR DE MINAS GERAIS}

RESUMEN: Tras conquistar más de 9.000 asentamientos en las últimas cuatro décadas y la continua construcción de la lucha por la tierra a través de las ocupaciones, los movimientos socioterritoriales actualmente también se preocupan por la orientación de los temas alimentarios, especialmente a través de las ideas de Soberanía Alimentaria enumeradas por Vía. Campesina. Como ejemplo, está el Movimiento de Trabajadores Rurales Sin Tierra (MST) que ha sido uno de los máximos exponentes de la lucha por la tierra y por la Soberanía Alimentaria, donde en Campo do Meio - MG, a través de Quilombo Campo Grande, encontramos estos dos facetas de la disputa territorial y el desarrollo. Junto con la perspectiva de la inseparabilidad, el trabajo se desarrolló como parte de las acciones de los programas de extensión de UNIFAL-MG en seguimiento a visitas de campo, comercialización y manifestaciones políticas. El principal aporte que ofrecemos con este trabajo es la discusión sobre cómo se ha constituido la lucha por la tierra y por la Soberanía Alimentaria en Quilombo Campo Grande y cómo las dos se entrelazan con objetivos comunes: oponerse al modelo hegemónico y plantear un desarrollo justo y sostenible contrario. a lo estipulado por el capitalismo.

PALABRAS CLAVE: Cuestión agraria; Agroecología; Campesinado; Soberanía alimentaria; Desarrollo territorial.

\section{INTRODUÇÃO}

A expansão do capital em sua atual fase globalizada, tem sido equiparada de um processo contraditório e problemático de acumulação, no qual sem quaisquer limites na busca incessável por lucro, ele tem trazido consequências desastrosas e predatórias em todas as suas dimensões (MESZÁROS, 2009). Um fator exemplificado desta crise está na questão agrária, que tem se consolidado enquanto um impasse global interligado a outros impasses como a ecologia e a 
democracia em concepções de que o capitalismo tem gerado o desgaste desses desafios e propondo falsas soluções irredutíveis (AMIN, 2013).

Fome, envenenamento por agrotóxicos, precarização, concentração de terras, desmatamento e destruição de recursos naturais - esses e diversos outros fenômenos podem ser enxergados no que corresponde a questão agrária na atual crise estrutural do capital - que no presente possui sua potencialidade em larga escala com consequências irreversíveis, e como ressaltado, mais do que nunca de maneira intensificada o seu aspecto destrutivo (MESZÁROS, 2009). Desse modo, considera-se aqui presente, a necessidade de buscar e construir alternativas subversivas que se contraponham à faceta destrutiva e potencializadora do capitalismo no que tange o mesmo em suas dimensões, em especial a questão agrária.

A questão agrária historicamente perpassa por um processo relevante de acumulação do capital, onde na leitura dos regimes alimentares têm se constituído dos seguintes: i) o regime imperial empenhado pela Grã-Bretanha (1870-1930), tendo como principal plano de fundo as revoluções industriais e o abastecimento da classe trabalhadora ali surgida; ii) o regime alimentar intensivo, centrado nos Estados Unidos (1950-1970), o qual estabeleceu os moldes da Revolução Verde, onde os EUA exerceram um papel influente nas adoções e propagações das novas técnicas surgidas na atual fase, distinto desses dois regimes e o iii) se manifesta globalmente, através da atuação de grandes corporações do ramo alimentar apoiadas no neoliberalismo de instituições e do mercado, sendo este o regime alimentar corporativo (McMICHAEL, 2016). Assim, atualmente a agricultura tem sido submetida às regras de concorrência do mercado de maneira intensificada, intensificando a constituição de uma agricultura sem agricultores e subordinada aos modos produtivos e destrutivos do mercado. 
Em contraponto a este modelo hegemônico, encontramos no campesinato a bandeira da Soberania Alimentar enquanto uma proposição contrária ao modelo instituído pelo regime corporativo (COCA, 2016), onde a mesma tem se consolidado enquanto um ideal de práxis pelo movimento global de camponeses La Via Campesina. Segundo o movimento, a Soberania Alimentar pode ser compreendida como o direito dos povos a alimentos saudáveis e culturalmente apropriados, assim como ecologicamente e socialmente consonantes, estabelecidos democraticamente entre os povos e nações (LA VIA CAMPESINA, 2008), sendo um modelo contraposto a própria crise capitalista em suas dimensões que se atrelam a questão agrária. Buscando romper com a atuação do capital financeiro e especulativo acerca da produção de alimentos e do controle sobre as terras:

La soberanía alimentaria: echando al capital especulativo fuera de los alimentos, y re-nacionalizando la producción y las reservas de alimentos, se ofrecería la única salida de la crisis alimentaria. Solo la agricultura campesina alimenta a los pueblos, mientras que el agronegocio produce productos de exportación y agrocombustibles para alimentar a los automóviles en lugar de los seres humanos. La soberanía alimentaria basada en la agricultura campesina ofrece la solución a las crisis (LA VIA CAMPESINA, 2008, não paginado, destaque nosso).

Dentre a atuação da La Via Campesina, encontramos distintos movimentos heterogêneos do Norte e Sul Global que não implicam na rejeição da modernidade ou da tecnologia, mas de um modelo alternativo construído com base em valores éticos e princípios, valorizando a própria localidade e todas suas interfaces (DESMARAIS, 2012) perspectivando um ideário comum, o da Soberania Alimentar. Dentre esses movimentos, encontramos no Brasil, o Movimento dos Trabalhadores Rurais Sem Terra (MST) que têm se constituído enquanto um movimento na luta pela terra e território (FERNANDES, 2012), fruto historicamente das distintas lutas constituídas pela terra no Brasil como Trombas e Formoso, 
Porecatu e atingidos pela construção de Itaipu (FERNANDES, 1996; STÉDILE; FERNANDES; 1999). O MST tem atuado também na luta pela Soberania Alimentar, algo presente principalmente no seu modelo expoente de Reforma Agrária Popular, enquanto algo que construa diretrizes de atuação do movimento em seus assentamentos e acampamentos, assim como na sociedade em geral (MST, 2009). Destaca-se também nesse plano de reforma agrária, o papel que a agroecologia passou a assumir, onde em sua abrangência enquanto ciência, prática e movimento (WEZEL, et. al., 2009) se demonstra enquanto modelo produtivo e sobretudo pedagógico dentro do movimento, enquanto concepção, método e projeto político (BARBOSA; ROSSET, 2017).

Além disso, podemos entender essa contraposição ao regime corporativo dentre os movimentos camponeses da La Via Campesina e em especial o MST, na própria leitura conceitual do território e possivelmente de sua luta por ele. O território pode ser compreendido enquanto um espaço adentrado de relações de poder (RAFFESTIN, 1992). O mesmo tem sido assimilado por óticas de desenvolvimento do capital, sendo enxergado enquanto um berço de recursos a serem explorados com finalidades acumulativas (PORTO-GONÇALVES, 2012) logo, no espaço agrário, sendo direcionado a um espectro de desenvolvimento para exportação de commodities e matéria prima. Esse espectro de desenvolvimento capitalista é confrontado pela própria constituição territorial que se antagonizam ao mesmo - dentre exemplificação, o próprio MST que se constitui um movimento socioterritorial, disputando com o latifúndio e o agronegócio terras agricultáveis e logo o território, mas também como ele pode se configurar nas perspectivas de desenvolvimento (FERNANDES; 2000).

Exemplos no próprio modelo produtivo elencado no desenvolvimento capitalista que dinamiza a produção de commodities do agronegócio estabelecida desde a Revolução Verde, onde a constituição de uma agricultura ecológica, emancipadora e adentrada à uma sinergia entre todos os fatores que a dinamize 
(ALTIERI, 2012) tem sido massificada pelo movimento (MST, 2009), mostrando que além da disputa material pela terra, sua reconfiguração material e imaterial é presente no objetivo de contraposição efetiva as manobras do capital e das corporações representativas do mesmo, não coincidente que na abordagem exercida na geografia agrária brasileira acerca da Soberania Alimentar, encontramos a mesma atrelada em grande parte na discussão envolvendo o conceito de território e suas nuances de desenvolvimento, ressaltando principalmente o papel dos movimentos socioterritoriais em sua construção (COCA, et. al., 2020).

Desse modo, buscar contraposição ao regime alimentar corporativo, assim como no capitalismo que o dinamiza, é sobretudo, partir da compreensão dos de baixo, e a luta por Soberania Alimentar se protagoniza nesse processo (McMICHAEL, 2016), assim como enxergar que essa luta resulta na territorialização e constituição territorial distinta das elencadas pelo Estado e mercado que atua em um desenvolvimento em prol dessas corporações (FERNANDES; 2000). Por conseguinte, buscaremos discorrer sobre a luta pela terra e Soberania Alimentar do MST a partir do território do Acampamento Popular Quilombo Campo Grande, em Campo do Meio, sul de Minas.

Sobretudo, levando em consideração que essa luta se constitui contra um modelo de desenvolvimento degradante em uma totalidade estrutural que se encontra em crise, nossos objetivos perpassam por constatar como a luta pela terra e por Soberania Alimentar têm se consolidado no Sul de Minas através do MST, assim como suas dimensões que se contrariam ao sistema agroalimentar corporativo que certamente encontra nos diversos territórios mineiros, apenas a finalidade exploratória e acumulativa. O presente trabalho se distribui nos tópicos de caracterização da área de estudo, os materiais e métodos utilizados, os resultados e discussões e por fim, as reflexões estabelecidas nas considerações finais. 


\section{ÁREA DE ESTUDO}

A escala de análise surge do Assentamento Popular Quilombo Campo Grande - MST em Campo do Meio - MG, onde através da relação entre pesquisa e extensão da UNIFAL-MG sede, localizada em Alfenas - MG, juntamente com o assentamento popular em Campo do Meio possibilitou as reflexões estabelecidas.

Ressaltamos, a princípio, que a região do Sul de Minas se destaca em um processo mundializado do mercado através, principalmente, da produção de café - estabelecendo na região uma territorialização do agronegócio - tanto no campo através das monoculturas estabelecidas e das relações de trabalho desempenhadas, como no urbano, através dos estabelecimentos e instituições vinculadas ao produtivismo do agronegócio (LINDNER; ALVES, 2019). Além disso, destacam-se as relações de trabalho na produção do café, onde são presentes práticas análogas à escravidão (SANTOS; SANTOS FILHO, 2020), assim como a espacialização intensa do uso de agrotóxicos que se destaca frente a outras regiões (BOMBARDI, 2017).

Alfenas é um município localizado na mesorregião sul/sudoeste de Minas Gerais, segundo o Instituto Brasileiro de Geografia e Estatística (IBGE) o município apresenta uma população estimada de 80.973 pessoas com uma densidade demográfica de 86,75 hab./km² , é sede da Universidade Federal de Alfenas e possui como municípios limítrofes Alterosa, Carmo do Rio Claro, Campos Gerais, Campo do Meio, Paraguaçu, Fama, Machado, Serrania, Divisa Nova e Areado.

Com 54,6 km de distância de Alfenas, se encontra Campo do Meio, localizada na mesma mesorregião com uma população estimada em 11.475 e densidade demográfica de 41,67 hab./ $/ \mathrm{km}^{2}$, sendo destaque nos setores agropecuário, silvicultura, exploração florestal e pesca, onde a mão-de-obra em grande escala predomina na cultura do café.

O mapa a seguir, representa os municípios de Campo do Meio, onde se localiza o acampamento e Alfenas, sede da UNIFAL-MG. 
Figura 1: Mapa de localização dos municípios de Alfenas e Campo do Meio-MG

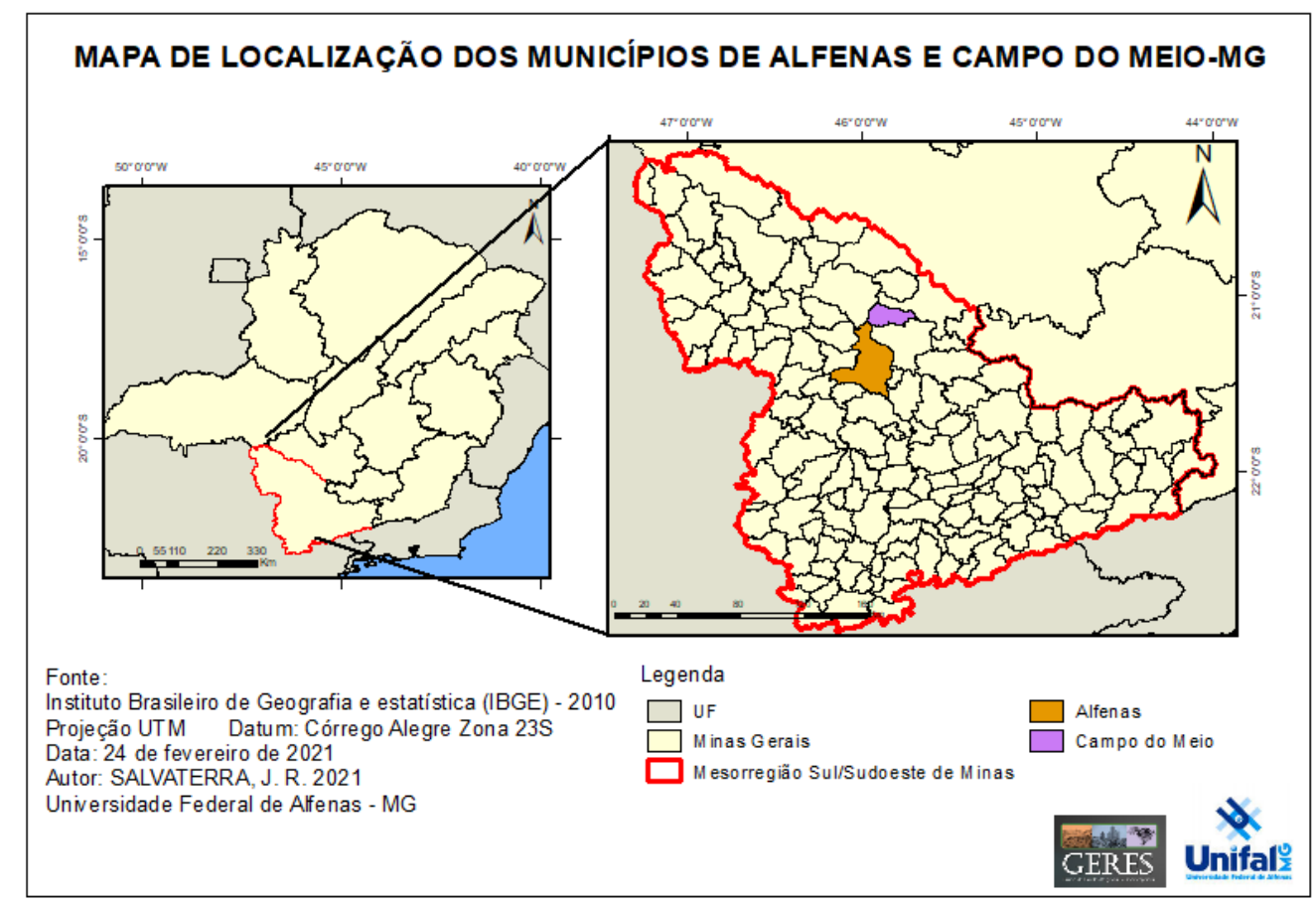

Fonte: Salvaterra (2021).

MATERIAIS E MÉTODOS

Partindo de preceitos da pesquisa ativista acadêmica vinculada aos estudos agrários críticos, apoiamos na modificação da realidade através do conhecimento científico juntamente com os movimentos que almejam essa modificação (BORRAS JR, 2016).

Encontramos, desse modo, uma incompatibilidade entre qualquer objeção positivista no exercício do presente trabalho, em razão das próprias intencionalidades inseridas ontologicamente nas relações entre sujeito e objeto que não se encontram em sobreposição, mas de modo no qual os mesmos se nivelam e se constroem - dialeticamente (SPOSITO, 2003). Desse modo, alinhado à perspectiva do ativismo acadêmico encontramos na observação participante como apontada por Brandão e Borges (2007), uma possibilidade metodológica onde estar/fazer/ser em meio aos grupos sociais no qual temos 
foco, passou a se constituir enquanto uma metodologia que se encontre juntamente ao método de práxis resultando também em um instrumento pedagógico e dialógico de aprendizado partilhado.

Quadro 1: Observação participante da pesquisa

\begin{tabular}{|c|c|c|c|}
\hline Estágio & Extensão & Ações & Pesquisas \\
\hline \multirow{2}{*}{$\begin{array}{c}\text { Cooperativa dos } \\
\text { Camponeses Sul } \\
\text { Mineiros - } \\
\text { CAMPONESA }\end{array}$} & \multirow[t]{2}{*}{$\begin{array}{c}\text { Fórum de } \\
\text { Combate ao } \\
\text { Uso de } \\
\text { Agrotóxicos } \\
\text { (2019) }\end{array}$} & \multirow{2}{*}{$\begin{array}{c}\text { Feira Agroecológica e Cultural } \\
\text { da UNIFAL; Certificação; Grupo } \\
\text { de Consumo Cestas } \\
\text { Agroecológicas Quilombo } \\
\text { Campo Grande; Jornadas } \\
\text { Universitárias da Reforma } \\
\text { Agrária; Visitas a campo } \\
\text { (conhecimento da produção e } \\
\text { organização territorial, despejo, } \\
\text { auxílio em serviços gerais); }\end{array}$} & $\begin{array}{c}\text { TCC: Lutando por } \\
\text { terra, trabalho e } \\
\text { alimento: uma análise } \\
\text { sobre os circuitos } \\
\text { agroecológicos do } \\
\text { Quilombo Campo } \\
\text { Grande. }\end{array}$ \\
\hline & & & $\begin{array}{c}\text { Iniciação científica: A } \\
\text { agroecologia do } \\
\text { campo à mesa do } \\
\text { consumidor: reforma } \\
\text { agrária e } \\
\text { abastecimento } \\
\text { alimentar no Sul } \\
\text { Minas Gerais }\end{array}$ \\
\hline
\end{tabular}

Fonte: Salvaterra (2021).

Desse modo, encontramos na extensão universitária uma possibilidade que engloba tanto o método como a metodologia proposta das intencionalidades inseridas nos sujeitos e objetos relacionados. Sendo a partir dos projetos de extensão Fórum de Combate ao Uso de Agrotóxicos (2019), Semeando a Terra (2020) e do Núcleo de Estudos Trabalho, Agroecologia e Soberania Alimentar (2021) a possibilidade de interpretação e construção ativa de se inserir em nossos objetivos. O quadro acima representa a síntese das ações geradoras do presente trabalho.

RESULTADOS E DISCUSSÕES 
A luta pela terra desempenhada pelo MST no Quilombo Campo Grande em Campo do Meio - MG, sobretudo, nos indica uma faceta antiga de lutas anteriores estabelecidas no seu território. Campo do Meio, Campos Gerais e Campo Belo, atuais municípios do Sul de Minas, constituíram anteriormente o Quilombo do Campo Grande, um dos maiores quilombos no Brasil (MARTINS, 2008), nome que inspira o atual acampamento popular do MST. Ressaltamos aqui, como anteriormente ao embate estabelecido na atualidade entre campesinato e agronegócio, já se encontrava uma gama de conflitos e violências desde o período colonial, com presença histórica de lutas de resistência e libertação (OLIVEIRA, 1989).

No que corresponde ao surgimento do atual território do MST, encontramos o mesmo no processo de intensificação do próprio capitalismo agrário e de suas barbaridades estabelecidas no território enxergado como berço de recursos exploratórios no processo de globalização (PORTO-GONÇALVES, 2012). Através do estopim modernizador elencado pela Revolução Verde, surgia também na metade do século passado a Usina Ariadnópolis, sendo a principal empregadora do município, elencada no auge do Pró-álcool - programa instituído durante a ditadura militar, visando o fomento à produção de álcool, tendo como principal intenção elencar o etanol.

No entanto, em 1996, a mesma faliu deixando em média meio milhão de dívidas trabalhistas, assim como o desmazelo do território resultante da monocultura intensiva de cana-de-açúcar. Contínuo a esse contexto, pode-se perceber as conflitualidades surgidas, em vista que a partir desse processo, houve um embate de destruição e surgimento de um novo território (FERNANDES, 2004).

A partir desse contexto, surgiu o levante de trabalhadores reivindicando seus direitos, onde uma das ações passou a se concretizar através das ocupações de terras que viriam a gerar a atual configuração do Quilombo Campo Grande. As ocupações, nesse processo, podem ser compreendidas como o estopim inicial de 
interação entre camponeses, migrantes, expropriados e desempregados que buscam não só a conquista da terra, mas perspectivas de vida que passem a eclodir em um espaço de luta e resistência (FERNANDES, 2004). Com pequenas parcelas do direito conquistado na terra através das ocupações iniciais datadas de 1996 a 1998, a conquista do Assentamento Primeiro do Sul, em 1997, surgiu para com a capacidade para 42 famílias (REDE DATALUTA, 2020). Sendo a participação conseguinte de 1200 famílias em outras ocupações - onde apenas em 2012 surgiu o Assentamento Nova Conquista II, com capacidade apenas para 12 famílias (Ibid.).

Considerando a insuficiência dos assentamentos frente a demanda pela terra, um grande aglomerado de famílias permaneceu e/ou chegou na área da antiga usina, composta atualmente por aproximadamente 450 famílias e 11 acampamentos: Sidney Dias, Rosa Luxemburgo, Tiradentes, Girassol, Fome Zero, Chico Mendes, Betinho, Irmã Dorothy, Vitória da Conquista, Potreiro e Resistência.

A luta pela terra no atual Quilombo Campo Grande, se dá naquilo que 400 Fernandes $(2000,2004)$ nos aponta enquanto conflitualidade entre os modelos de desenvolvimento territorial constituídos pelo MST e aqueles do mercado capitalista. Seguindo as constatações da antiga Usina enquanto uma expoente de territorialização da agricultura capitalista em Campo do Meio - MG, a mesma instaurou uma lógica de desenvolvimento que culminou na exploração, degradação e desmazelo para com os trabalhadores assim com a natureza. No entanto, a partir da coalizão de luta pela terra e de interesses comuns, constatase aqui a territorialização do MST no sul de Minas como contraposta à desempenhada pelo agronegócio.

Sobretudo na conquista de seus dois assentamentos, logo territórios conquistados, não culminou em sanar o conflito agrário, onde, sobretudo, os acampados ainda permanecem na luta tendo ao lado os assentados e nos trabalhos desempenhados coletivamente entre os mesmos (FERNANDES, 2004), 
assim como buscando não só a disputa no plano material do território, passou também a desempenhar uma lógica distinta de desenvolvimento que possibilitasse a restauração e novos horizontes para esse território surgido. A figura 2, representa um dos despejos sofridos no Quilombo Campo Grande, sendo este ocorrido inicialmente em 12 de agosto de 2020, no qual algumas famílias acampadas perderam sua produção e também a escola do campo Eduardo Galeano que fora destruída. No despejo se tornou perceptível a resistência elencada pelos camponeses, onde muitos já haviam passados por situações semelhantes e não decidiram acatar as decisões institucionais de expropria-los, permanecendo em tenência por 3 dias consecutivos em barreiras e solidariedade contra as ações policiais.

Escolhemos a mesma, pois acreditamos que simboliza a conflitualidade existente acerca dos interesses antagônicos entre os acampados, mercado e Estado. No qual ressaltamos novamente o período de vigência da pandemia que totalizava no momento 100.000 mortes - não sendo um entrave para o estado, que se manteve presente na truculência durante a reintegração de posse com bombas de gás lacrimogêneo e avanço das tropas de Choque. Contrariamente, os camponeses se sujeitaram neste momento sobretudo da resistência e solidariedade, que não só mobilizou o seu território, mas trouxe uma rede de solidariedade entre diversos movimentos locais, regionais, nacionais e globais.

Como observado na figura, temos nessa ocasião de despejos uma tipificação dos modelos de desenvolvimento em disputa: o do campesinato, que luta por moradia, alimentação, trabalho e dignidade de um lado e, do outro, o Estado agindo em prol do mercado e dos grandes latifundiários, visando o lucro com consequências degradantes e desumanizadoras para com os sem-terra.

FIGURA 2: Despejo ocorrido no Quilombo Campo Grande, em agosto de 2020 


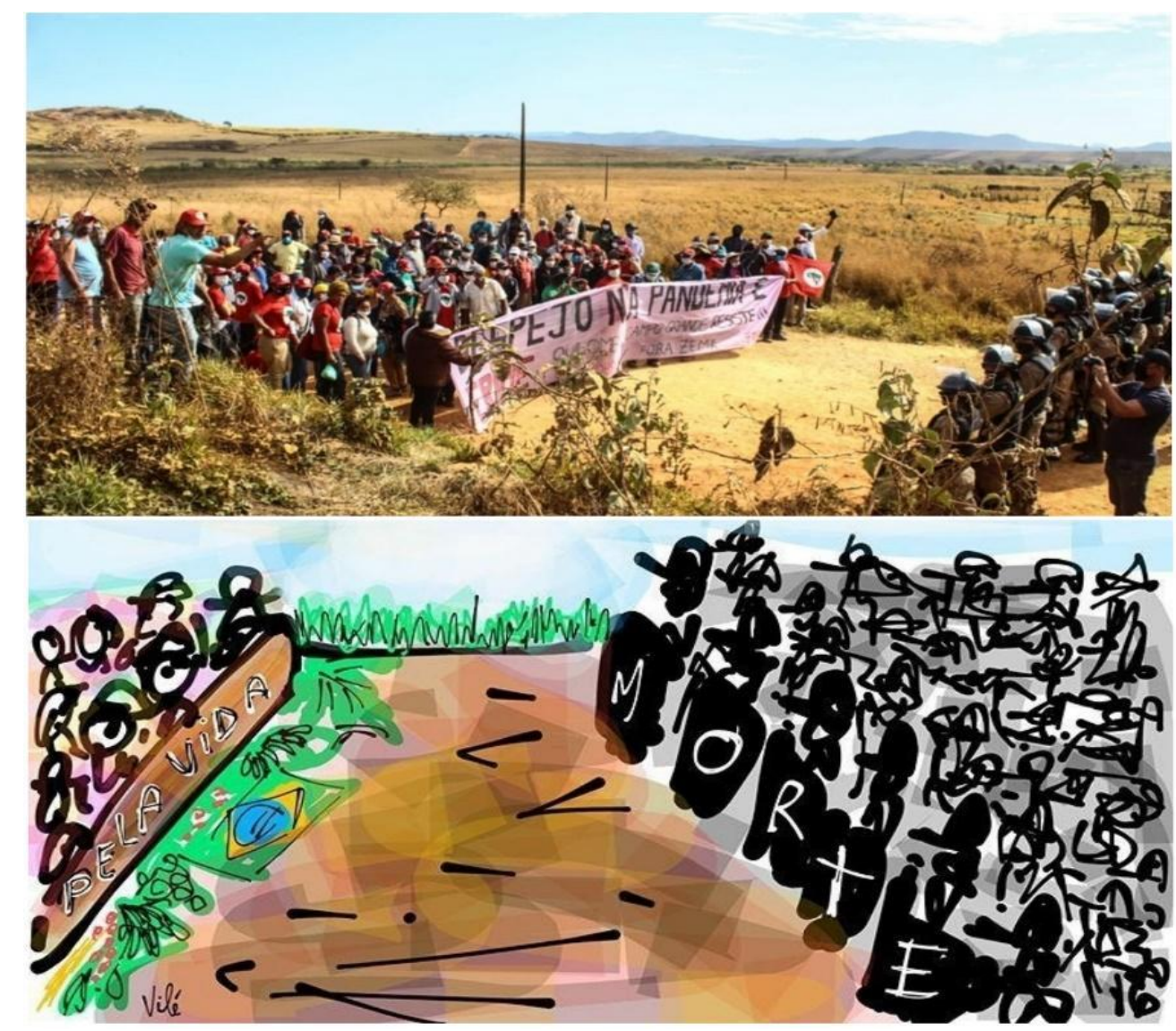

Fonte: Brasil de Fato (2020) e Vilé (2020).

O despejo ocorrido em 2020, tipifica o conflito no qual Fernandes (2004, p. 27) nos apresenta enquanto algo dentro da conflitualidade alimentada dia-a-dia pelo desenvolvimento capitalista:

A conflitualidade é uma propriedade dos conflitos e está relacionada, essencialmente, à propriedade da terra, à renda da terra, à reprodução capitalista do capital, consequentemente à concentração da estrutura fundiária e aos processos de expropriação dos camponeses e assalariados por diversos meios e escalas e bases sociais, técnica econômica e política. A resposta é a luta pela terra, reforma agrária, resistência na terra e a perspectiva de superação da questão agrária.

Dentre a luta pela terra desempenhada na constituição do atual território do Quilombo Campo Grande - a disputa não permaneceu somente no campo material com base na luta pela terra, mas também na constituição de uma lógica 
de desenvolvimento que se antagoniza à exercida pela falida usina Ariadnópolis. Como retomado nas proposições de Fernandes (2004, p. 27):

(...) Esses processos não se referem apenas à questão da terra, mas também às formas de organização do trabalho e da produção, do abastecimento e segurança alimentar; aos modelos de desenvolvimento da agropecuária e seus padrões tecnológicos, às políticas agrícolas, às formas de inserção ao mercado e aos tipos de mercado; à questão campo - cidade, à qualidade de vida e dignidade humana. Por tudo isso, a questão agrária compreende as dimensões econômica, social, ambiental, cultural e política. A questão agrária é antes de tudo uma questão territorial.

Partindo desse contraponto de desenvolvimento, podemos buscar não só no conflito no qual a escola foi destruída em um ato não apenas material, mas simbólico devido a representação que a mesma possui para os camponeses do Quilombo Campo Grande (COCA, et. al., 2021) mas podemos entender na própria produção e comercialização do território, como a perspectiva de desenvolvimento se antagoniza ao projeto existente do mercado e do Estado.

Nesse caso, temos o protagonismo da Cooperativa dos Camponeses Sul Mineiros (CAMPONESA) como a expoente organizativa da produção do Quilombo Campo Grande, motivada na coletivização da organização econômica e social da produção desde 2012 "[...] tendo como objetivo social proporcionar melhor qualidade de vida e inclusão social aos camponeses sul mineiros, para o fortalecimento da solidariedade e da Agroecologia" (GUAlí, 2015, não paginado). Através da mesma, encontramos a produção de assentados e acampados com caráter agroecológico ou em transição, tendo destaque para o café, açúcar mascavo, farinha de mandioca e milho, feijões, fubá, molhos, pimentas, rapaduras, doces e geleias. Esses produtos possuem sua comercialização nos Armazéns do Campo do MST pelo Brasil, em grupos de consumos e em vendas diretas estabelecidas pela cooperativa. Conjuntamente, não podemos reduzir a produção apenas a estes produtos beneficiados - assim como sua 
comercialização visando localidades externas, pois sua produção é estabelecida de forma diversa e a comercialização também ocorre nas próprias localidades.

A Soberania Alimentar no Quilombo Campo Grande pode ser observada pelas próprias famílias que compõem seu território. Em distintas visitas a campo, encontramos uma diversidade produtiva que em casos é comercializada, e em outros destina-se para o próprio consumo. Partindo da comercialização estabelecida pelo movimento, pudemos observar essa diversidade para além dos produtos beneficiados na cooperativa, mas na própria logística de comercialização uma parte das produções familiares.

$\mathrm{Na}$ comercialização com base nos modelos visando a localidade, encontramos primordialmente a análise de uma parcela produtiva do acampamento. Através da comercialização das Cestas Agroecológicas Quilombo Campo Grande - ação surgida durante a pandemia da Covid-19, com entregas para os municípios próximos, podemos observar uma parcela produtiva, no qual algumas famílias vêm atuando, todas certificadas pela associação Orgânicos Sul de Minas, ou em transição para certificação. As nuvens de palavras abaixo foram constituídas com base no acompanhamento e logística do grupo de consumo com entregas em Alfenas-MG através do ano de 2020 e 2021, onde os produtos comercializados correspondem enquanto um ponto fundamental para compreender essa produção²:

Figura 3: Verduras, legumes, tubérculos e raízes cultivados e produzidos no Quilombo Campo Grande

\footnotetext{
${ }^{2}$ Os produtos das nuvens de palavras não possuem finalidade de representação quantitativa, mas sim de apresentar uma parcela da diversidade produtiva. As nuvens foram geradas em acompanhamento a comercialização semanal durante um ano. Onde o tamanho representa a demanda.
} 


\section{Verduras, Legumes, Tubérculos e Raízes}

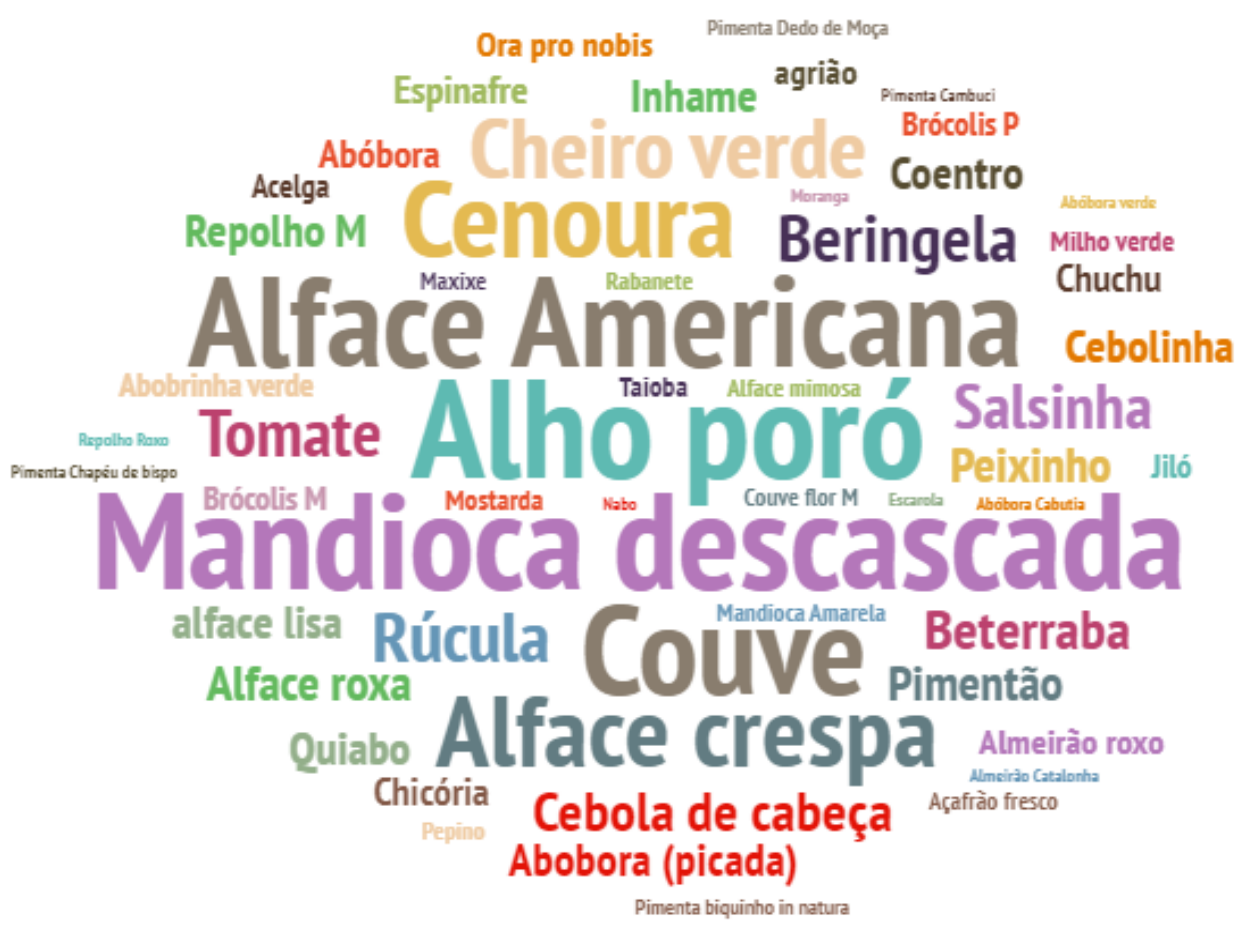

Fonte: Salvaterra (2021).

Salientamos aqui que a comercialização não ocorre espontaneamente em modelos convencionais, mas nas próprias vendas diretas e no resgate do alimento politizado oriundo da luta pela terra enquanto agente transformador da realidade envolvendo campo e cidade (CALVÁRIO; DESMARAIS, 2020), sendo o caso das cestas agroecológicas uma expressão do próprio MST em escala nacional que se instrui nas localidades como demonstrado.

Além disso, destacamos a comercialização do Quilombo Campo Grande em distintos espaços como as vendas in loco; as feiras em Campo do Meio-MG assim como a Feira Agroecológica e Cultural da Unifal-MG parceria constituída desde o ano de 2019; festivais da reforma agrária; eventos científicos; restaurante universitário; cooperativas parceiras; e os armazéns do campo em dinâmica online ou presencial. 
Figura 4: Frutas e polpas de frutas produzidas pelo Quilombo Campo

Grande

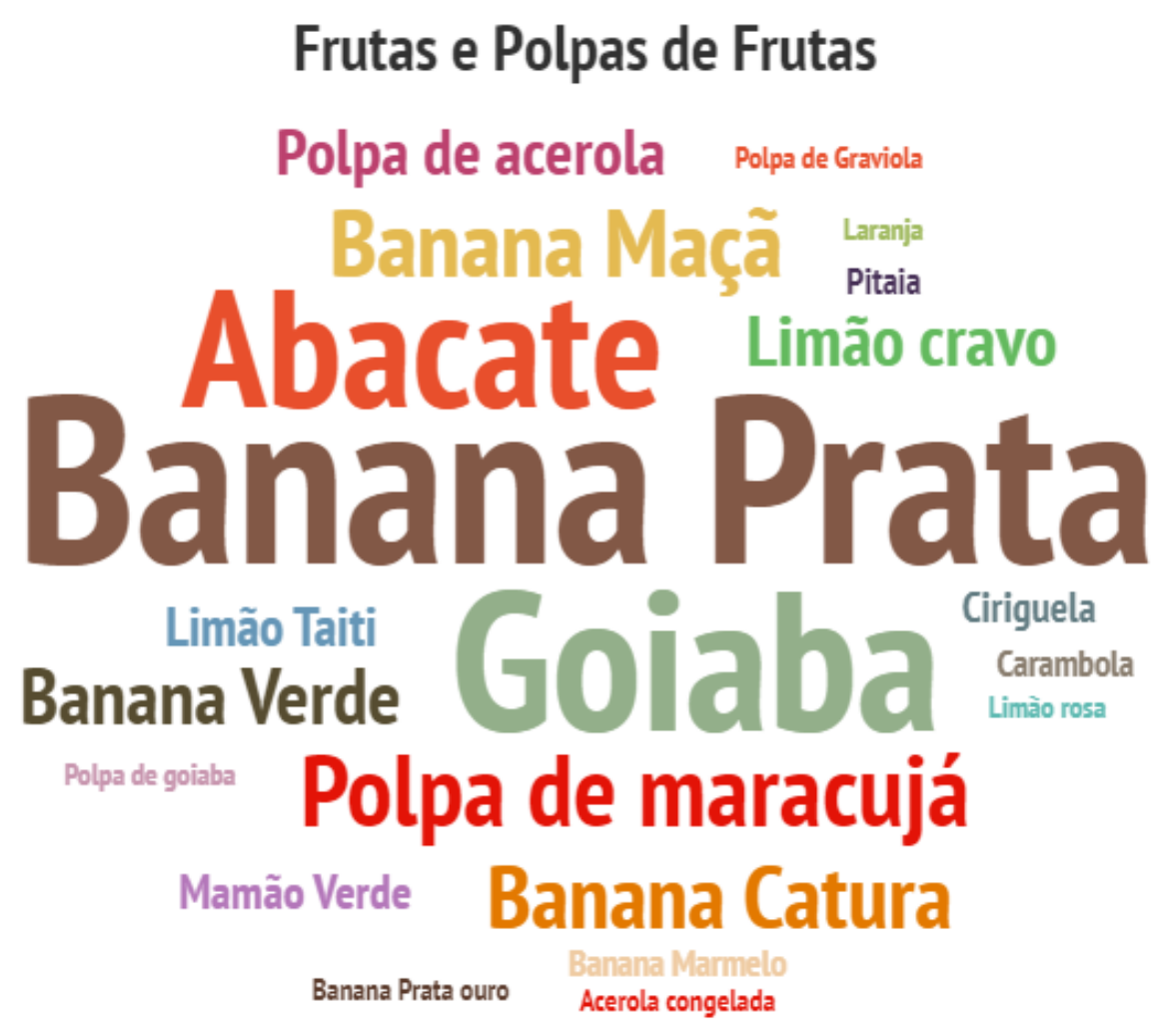

Fonte: Salvaterra (2021).

A produção comercializada do Quilombo Campo Grande se estabelece em grande parte pela atuação das famílias que além da comercialização que propicia a Soberania Alimentar para os consumidores urbanos, ainda se encontra enquanto a Soberania Alimentar ao consumo próprio das famílias e do acampamento.

FIGURA 5: Plantas medicinais, aromáticas e fitoterápicos produzidas pelo Quilombo Campo Grande 


\section{Plantas Medicinais, Aromáticas e Fitoterápicos}

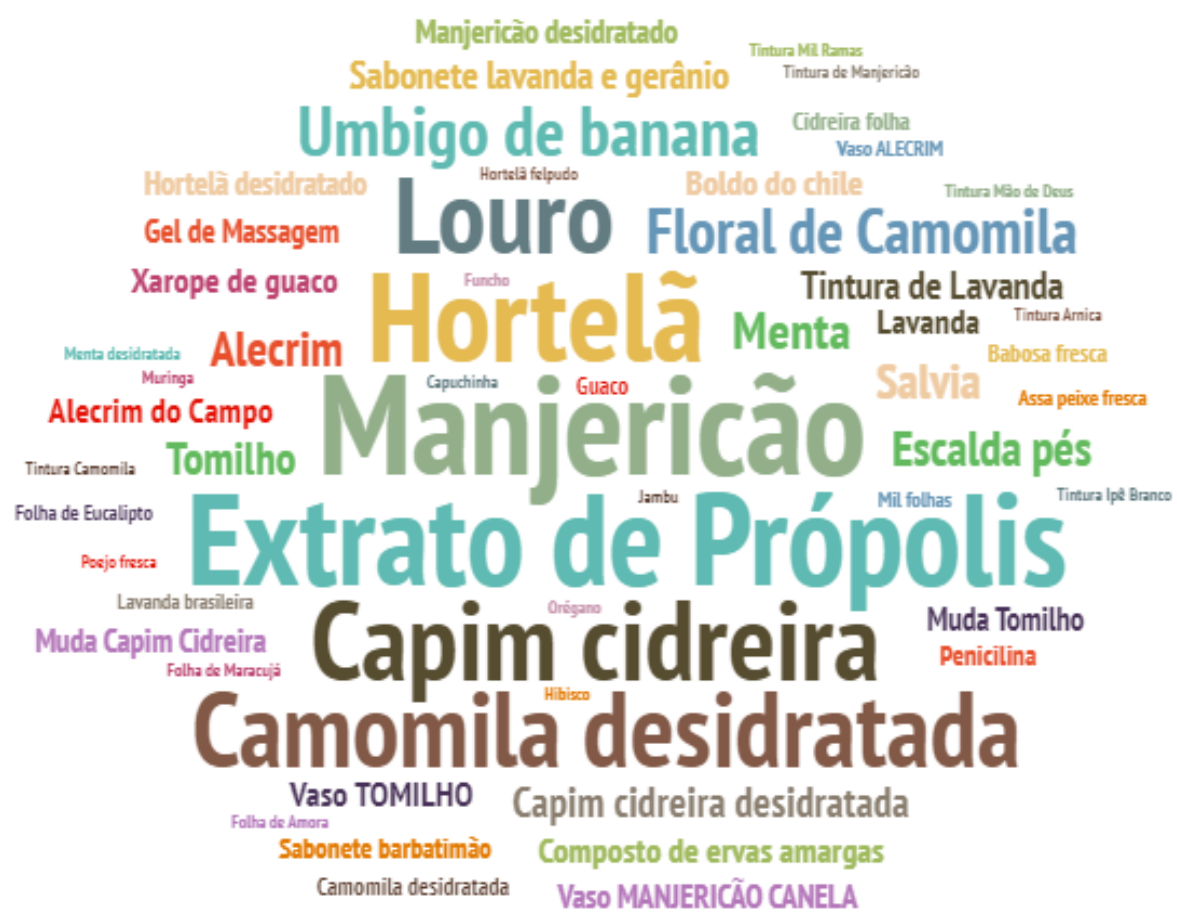

Fonte: Salvaterra (2021).

Ressaltamos aqui as Plantas Medicinais, Aromáticas e Fitoterápicos desempenhadas pelo Coletivo de Mulheres Raízes da Terra - em uma proposição coletiva de produção entre as mulheres, exercendo além da geração de renda, uma possibilidade de compartilhamento de saberes e da luta de mulheres camponesas, além de propiciar acesso aos consumidores urbanos:

Os alimentos são de muita qualidade, principalmente que são orgânicos. A venda de alguns preparos, tinturas, própolis são muito interessantes pra mim. Sinto confiança de comprar e de divulgar para as pessoas próximas. Geleia de mercado nem se compara com a qualidade da geleia produzida pelo Quilombo. O fato de ter entrega, poder escolher os produtos pelo smartphone também são facilitadores importantes [Consumidora da Cesta Agroecológica 27/02/2021].

Os produtos acima assim como o depoimento da consumidora evidenciam não só a comercialização, no entanto a própria Soberania Alimentar do 
acampamento. Se anteriormente se firmava enquanto um território de monocultura, hoje é através da diversidade que o mesmo se caracteriza. Destacamos em nossas próprias visitas a campo, como no processo de certificação em como é estabelecida essa produção. Dialogando como uma ciência, prática e movimento (WEZEL, et. al., 2009) a produção agroecológica no Acampamento é antes de tudo política envolvendo concepções dos próprios camponeses em caminho de projetos políticos e emancipatórios (BARBOSA; ROSSET, 2017) e, em vista que a maioria dos produtores sequer possuem a terra enquanto uma garantia, mas se instruem de construir a partir da luta pela mesma, perspectivas distintas da hegemônica e que possam dinamizar sua autonomia e libertação acerca não só do acesso a terra, mas dos caminhos de desenvolvimento nela, não obstante que mesmo com as instabilidades exercidas pela conquista da terra, a agroecologia aqui se manifesta enquanto uma territorialidade exercida no Quilombo Campo Grande (COCA, et. al., 2019).

Outrora, a partir do regime alimentar corporativo (MCMICHAEL, 2016), a dinamização da questão agrária estabelece não só o controle da terra por parte das grandes corporações, logo a luta pela conquista da mesma sendo contínua, mas também o controle sobre o mercado, logo a produção, circulação e consumo. Sendo a Soberania Alimentar se inserindo também enquanto uma práxis contínua pelos movimentos camponeses, e no caso do Quilombo Campo Grande, essa luta entrelaçada com a própria luta pela terra que vem sendo desempenhada no século XXI. Exemplo de conflito que marca essa conflitualidade está no próprio café comercializado pelo Quilombo Campo Grande, cujo qual não apresenta somente um diferencial aos outros cafés convencionais produzidos na região, mas se encontra em uma denúncia para com as práticas exercidas nas culturas destes cafés, como exemplo da campanha "No Meu Bule Não".

A campanha “No Meu Bule Não” encabeçada pelo Quilombo Campo Grande em parceria com o Centro de Referências de Direitos Humanos (CRDH) têm 
confrontado os latifundiários e antigos donos da antiga usina Ariadnópolis, que veem no território do Quilombo Campo Grande a oportunidade de (re)inserir a monocultura do café a fim de aumentar sua acumulação para o mercado externo. A campanha surgiu em 2018, frente às ameaças e despejos que vieram a acontecer depois. A mesma teve como objetivo a denúncia ao despejo que em si está entrelaçada com o próprio consumo de café de marcas que se inserem nesse sistema convencional. Dentre as empresas denunciadas está: Nescafé; Nespresso; Pilão, Caboclo; Senseo; L'or; Café Pelé; Café do Point; e Damasco.

Pegamos o café enquanto exemplo para demonstrar como o consumo em si é algo estritamente relacionado com a questão agrária, onde marcas que constituem um poder hegemônico corporativo enxergam nas propriedades que não se inserem na lógica da mesma uma oportunidade de expropria-las e expandir essa produção. Entretanto, o MST e o Quilombo Campo Grande representam um combate a essa própria lógica, permanecendo e lutando pela terra, produzindo e denunciando aquele que representa um modelo antagônico ao seu, e que, além disso, não gera desenvolvimento, apenas de modo discursivo - apontando alternativas que se mostram cada vez mais necessárias.

FIGURA 6: Síntese do Quilombo Campo Grande 


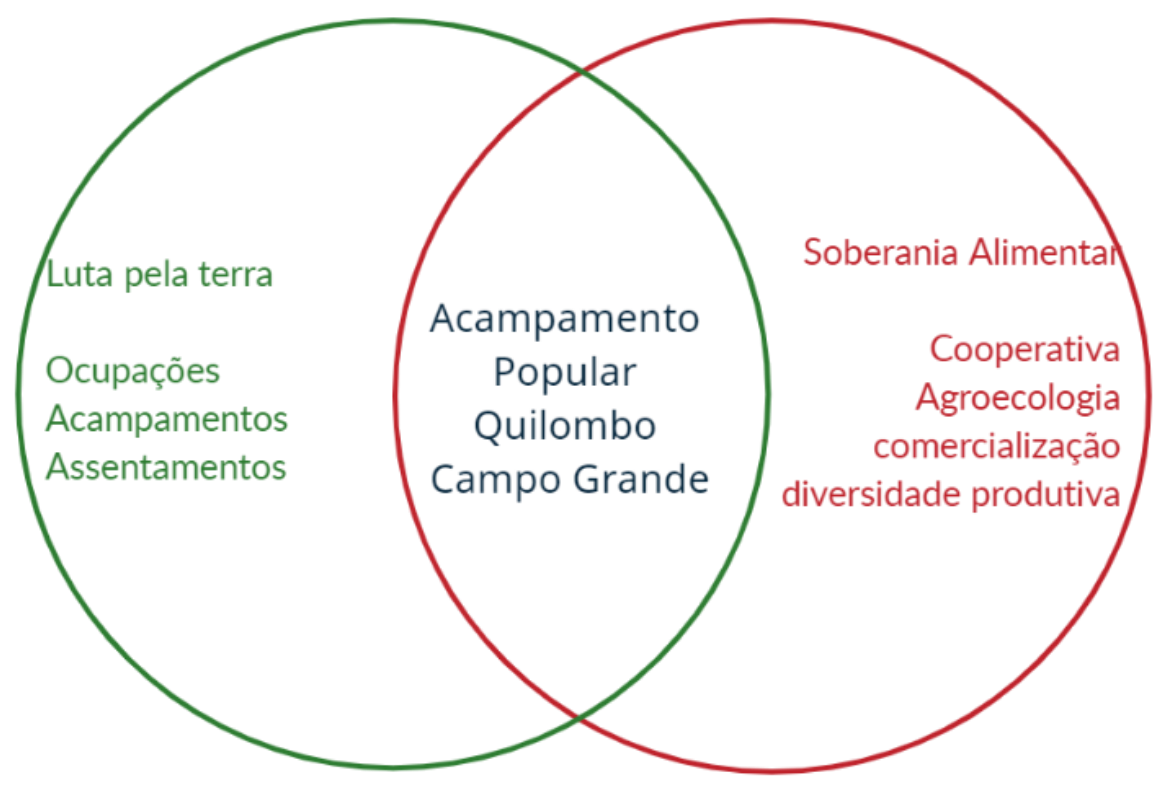

Fonte: Salvaterra (2021).

\section{CONSIDERAÇÕES FINAIS}

Em síntese, são distintos os desafios que corroboram para a junção da luta pela terra e da Soberania Alimentar. Primeiramente, há de se ressaltar o papel da materialidade na realidade objetiva, a conquista da terra é sem dúvidas, um grande passo para o desenvolvimento da Soberania Alimentar através, por exemplo, da agroecologia. No entanto, no Quilombo Campo Grande - assim como em outros acampamentos, a luta se constitui cotidianamente entrelaçada, repleta de desafios, no qual sem dúvidas o maior deles se concentra na disputa contra o latifúndio/agronegócio territorializado na região.

Um exemplo está no despejo ocorrido em agosto de 2020, onde pudemos constatar nos três dias de resistência dos camponeses, como a brutalidade exercida pelo Estado, não destruiu somente a sua escola e algumas casas - mas também assolou perspectivas de diversos camponeses acerca de seu futuro e desenvolvimento. No entanto, historicamente o campesinato resiste, e através da luta pela terra do Quilombo Campo Grande, é perceptível como os mesmos camponeses se mantiveram firmes e não se retraíram para a justiça burguesa defensora dos latifundiários. 
A luta pela terra no Quilombo Campo Grande é constante desde a sua existência após a falência da antiga usina, e com o tracejar do MST em escala nacional, através das proposições existentes na Reforma Agrária Popular e do fortalecimento do ideário da Soberania Alimentar pela Via Campesina, encontramos não somente uma luta pela terra enquanto objetivo único, mas a construção de um modelo de desenvolvimento territorial que questione o desenvolvimento capitalista e aponta caminhos distintos da barbárie estabelecida hegemonicamente.

Sobretudo, é esse o desafio da sociedade global: buscar proposições que insira moradia, alimentação, ecologia, democracia, saúde e diversas outras emergências que se correlacionam fruto do próprio desenvolvimento capitalista, e no caso do MST e em específico do Quilombo Campo Grande, encontramos essas lutas inseridas em conjunto na luta pela terra e Soberania Alimentar - o que já corrobora em si para um olhar atento, de que o ruir do capitalismo certamente virá dos de baixo e certamente o campesinato possuirá papel expressivo nesse processo.

\section{AGRADECIMENTOS}

Agradecemos sobretudo a parceria com o Acampamento Popular Quilombo Campo Grande do MST. Logo após, a Pró - Reitoria de Extensão (PROEX); ao curso de Geografia da UNIFAL-MG; ao Programa Institucional de Bolsas de Iniciação Científica (PROBIC/UNIFAL) e ao Conselho Nacional de Desenvolvimento Científico e Tecnológico (CNPQ).

\section{REFERÊNCIAS BIBLIOGRÁFICAS}

ALTIERI, M. Agroecologia, agricultura camponesa e Soberania Alimentar. Revista NERA, n. 16, p. 22-32, 2012. 
AMIN, S. Três desafios principais: democracia, questão agrária, ecologia, 0 COMUNEIRO, v. 17, 2013. Disponível em: https://www.ocomuneiro.com/ Acesso em 03 de out. 2021.

BARBOSA, L. P.; ROSSET, P. M. Educação do campo e pedagogia camponesa agroecológica na América Latina: Aportes da La Via Campesina e da CLOC. Educação \& Sociedade, v. 38, p. 705-724, 2017.

BOMBARDI, L. M. Geografia do uso de agrotóxicos no Brasil e conexões com a União Europeia. São Paulo: FFLCH - USP; 2017.

BORRAS JR, S. M. Land politics, agrarian movements and scholar-activism. 2016. Disponível em: https://www.tni.org/en/publication/land-politics-agrarianmovements-and-scholar-activism. Acesso em 22 de out. 2021.

BRANDÃO, C. R.; BORGES, M. C. A pesquisa participante: um momento da educação popular. Revista de Educação Popular, v. 6, n. 1, 2007.

BRASIL DE FATO. Acampamento do MST em MG é alvo de despejo em meio à pandemia: forças policiais realizam ação contra famílias do quilombo campo grande na madrugada desta quarta (12). 2020. Redação Brasil de Fato. Disponível em: https://www.brasildefato.com.br/2020/08/12/acampamento-do-mst-em-mge-alvo-de-despejo-em-meio-a-pandemia. Acesso em: 24 Out 2021.

CALVÁRIO, R.; DESMARAIS, A. A. Solidarities from below in the making of emancipatory rural politics: insights from food sovereignty struggles in the Basque Country. Sociologia Ruralis, v. 60, n. 4, p. 857-879, 2020.

COCA, E. L. F. 20 anos da proposta de Soberania Alimentar: construindo um regime alimentar alternativo. Revista NERA, v. 1, p. 14-33, 2016.

COCA, E. L. F. et al. A soberania alimentar na Geografia Agrária brasileira. Revista Terra Livre, v. 1, n. 54, p. 586-615, 2020.

COCA, E. L. F. et al. Agroecologia e territorialidades camponesas em Campo do Meio - MG. Revista Campo-Território, v. 14, n. 34 Dez., 2019.

COCA, E. L. F. et al. Quando para impedir a reforma agrária vale até destruir escolas: a direita autoritária contra o acampamento Quilombo Campo Grande, em Campo do Meio - MG. Boletim DATALUTA, n. 151, p. 01-09, 2020.

DESMARAIS, A. A. La Vía Campesina. The Wiley-Blackwell Encyclopedia of Globalization, 2012. 
FERNANDES, B M. Movimentos socioterritoriais e movimentos socioespaciais: contribuição teórica para uma leitura geográfica dos movimentos sociais. Revista NERA, n. 6, p. 24-34, 2012.

FERNANDES, B. M. MST: formação e territorialização. São Paulo: Hucitec, 1996.

GUAIÍ - COOPERATIVA CAMPONESA. Quem Somos - Cooperativa Camponesa, Assentamentos, Missão Visão e Valores, Organização, Coletivo e Mulheres, Amigos e parceiros. 2015. Disponível em: https://guaii.com.br. Acesso em 03 out. 2021.

LINDNER, M.; ALVES, F. D. Agronegócio do café no Sul de Minas Gerais: territorialização, mundialização e contradições. Revista Okara: Geografia em debate, v. 14, n. 2, p. 433- 451, 2020.

MARTINS, T. J. Quilombo do Campo Grande: História de Minas que se devolve ao povo. Tejota Editor, 2018.

McMICHAEL, P. Regimes alimentares e questões agrárias. Tradução de Sonia Midori. 1. Ed. São Paulo: Editora Unesp e UFRGS, 2016.

MÉSZÁROS, I. A crise estrutural do capital. Boitempo Editorial, 2009.

MST. A reforma agrária necessária: por um projeto popular para a agricultura brasileira. MST, 2009. Disponível em: https://mst.org.br/2009/05/20/nossaproposta-de-reforma-agraria-popular/. Acesso em: 03 out. 2021.

PORTO-GONÇALVES, C. W. Os Porquês da desordem mundial: o desafio ambiental. Rio de Janeiro: Ed. Record, 2012.

RAFFESTIN, C. Por Uma Geografia do poder. Tradução Maria Cecília França. São Paulo: Editora Ática, 1993.

REDE DATALUTA. Banco de Dados da Luta pela Terra. Presidente Prudente: Rede DATALUTA, 2020.

SANTOS, A. P. SANTOS FILHO, J. F. A economia colonial do café e o trabalho análogo ao escravo no Sul de Minas Gerais In: Alves, F. D.; Azevedo, S. C. (Orgs.). Análises geográficas sobre o território brasileiro: dilemas estruturais à Covid-19. 1ed. Alfenas: Unifal-MG, 2020, v. 1, p. 271-283.

SPOSITO, E. S. Geografia e filosofia: contribuição para o ensino do pensamento geográfico. São Paulo: Edunesp, 2003.

STEDILE, J. P.; FERNANDES, B. M. Brava gente. A trajetória do MST e a luta pela terra no Brasil. São Paulo: Perseu Abramo, 1999. 
VIA CAMPESINA. Carta de Maputo: V Conferencia Internacional de La Via Campesina, 2008. Disponível em: https://viacampesina.org/es/carta-de-maputo-vconferencia-internacional-de-la-vcampesina/ Acesso em: 03 out. 2021.

WEZEL, A., et al. Agroecology as a science, a movement and a practice. A review. Agronomy for sustainable development, v. 29, n. 4, p. 503-515, 2009. 